\title{
O uso da metodologia da problematização para a investigação sobre avaliação da aprendizagem. O que há de específico para o ensino superior?
}

\author{
The use of the problematization methodology for the investigation of \\ learning assessment. What is specific in the case of higher education?
}

\author{
Katiane Cavalcante de Moraes $^{1}$; Neusi Aparecida Navas Berbel ${ }^{2}$
}

\section{Resumo}

\begin{abstract}
Este estudo apresenta uma investigação das práticas adotadas por professores universitários na avaliação da aprendizagem. Utilizou-se a Metodologia da Problematização, por meio do Arco de Maguerez, constando de cinco etapas: Observação da Realidade e definição do problema, Pontos-chave a estudar, Teorização, Hipóteses de Solução e Aplicação à Realidade. Como observação da realidade, foram entrevistados professores do ensino fundamental e médio e realizou-se um resgate de memória das práticas avaliativas vivenciadas pelas autoras. O problema definido foi "O que há de específico, na avaliação da aprendizagem, para o Ensino Superior?”. Foram salientados quatro pontos-chave: 1-Os objetivos pretendidos no ensino superior conforme a literatura. 2-Modalidades avaliativas existentes na literatura. 3-As exigências da Instituição de Ensino Superior quanto à avaliação. 4-As avaliações praticadas na UEL. Para a teorização, utilizou-se a revisão de literatura, a análise de entrevistas com docentes da UEL e a análise de documentos oficiais da instituição. Concluiu-se que as práticas avaliativas mais específicas do nível de ensino superior são: publicação de artigos, participação em projetos, seminários e trabalhos de campo. Nas hipóteses de solução, constaram a publicação e divulgação da pesquisa. Como aplicação da pesquisa, o compromisso das autoras é de divulgá-la e utilizarem-se dos resultados em sua própria atuação profissional.
\end{abstract}

Palavras-chave: Práticas de avaliação. Ensino Superior. Metodologia da Problematização.

\begin{abstract}
This study presents an investigation about the university teachers' practices regarding the theme learning's assessment. The Problematization Methodology was used, through the Arch of Maguerez, consisting on five stages: Observation of the Reality and the problem's definition, Key-points to study, Theorization, Hypotheses of Solution and Application to the Reality. As observation of the reality, teachers of the fundamental and medium teaching were interviewed and took place a ransom of memory of the practical lived evaluation by the authors. The defined problem was "What is specific in the learning's assessment in the case of Higher Education"? There was pointed four Key-points: The objectives intended in the Higher Education according to the literature; Assessment modalities existent in the literature; The exigency of the Higher Education as to assessment; The practiced assessment in the UEL. For the theorization, the literature revision was used, analysis of interviews with UEL educational and the analysis of the institution official documents. It was ended that the more specific practical evaluation exercised Higher Education are: publication of articles, participation in projects, seminars and field works. In the solution hypotheses, the publication and popularization of the research were consisted. As Application of the research, the author's commitment is to diffuse and use the results in its own professional performance.

Key words: Assessment practices. Higher Education. Methodology Problematization.
\end{abstract}

1 Aluna do curso de Pedagogia da Universidade Estadual de Londrina. E-mail: katianemoraes@ pop.com.br.

2 Professora do Departamento de Educação da UEL e do curso de Mestrado em Educação. E-mail: berbel@uel.br 


\section{Introdução}

A avaliação não está presente somente nas salas de aulas, mas a encontramos constantemente no nosso dia-a-dia. Com efeito, precisamos avaliar-nos continuamente, para que possamos melhorar as nossas ações, assim como necessitamos avaliar os aspectos do mundo que nos rodeia, para nele nos situarmos.

Este trabalho foi realizado como parte das atividades de Iniciação Científica, e teve o intuito de conhecer o que há de específico nos procedimentos/ instrumentos avaliativos utilizados nas licenciaturas. Utilizou-se, como meio de investigação, a Metodologia da Problematização com o Arco de Maguerez, pois acreditamos que: "Por esse processo de análise da realidade, os alunos passam de uma visão sincrética, geral e precária, para uma visão sintética, mais elaborada sobre a prática". (BERBEL, 1995, p.12).

A presente pesquisa foi construída de acordo com os passos da própria Metodologia, conforme demonstrado no esquema a seguir:

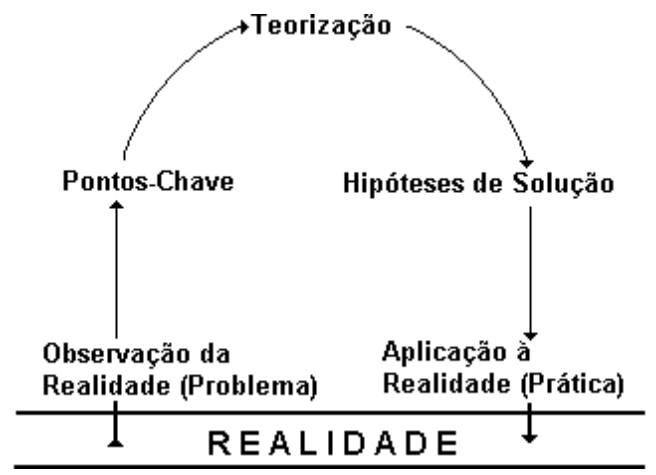

Figura 1. Arco de Maguerez (apud BERBEL, 1995).

No primeiro momento, procuramos observar a realidade em busca de uma questão de estudo. Verificamos alguns meios avaliativos empregados nos diferentes níveis de escolaridade, e a partir dessa verificação definimos e explicitamos o objeto de estudo. Refletimos acerca dos possíveis fatores e condicionantes maiores desse processo e buscamos encontrar os pontos-chave que envolviam o problema, a fim de aprofundar na teorização. A seguir, apontamos as possíveis hipóteses de solução políticopedagógicas para o problema, direcionando-nos para a etapa seguinte. Sendo assim, concluímos o trabalho, com a aplicação à realidade, e apontamos os meios pelos quais nossa investigação será disseminada. Descrevemos a seguir o desenvolvimento de cada uma das etapas da investigação.

\section{Observação da Realidade}

A primeira etapa da Metodologia da Problematização (BERBEL, 1995; BERBEL, 1999) tem como uma de suas características a observação da realidade selecionada para o estudo, e isso nos possibilita perceber os aspectos instigantes e os problemas que estão ali presentes.

Como forma de observação, optamos por utilizar um questionário a alguns professores do ensino médio e fundamental, com o intuito de conhecer os procedimentos / instrumentos avaliativos utilizados nestes níveis de ensino. A seguir, foi feita uma reflexão acerca dos instrumentos utilizados nos três níveis de ensino (fundamental, médio e superior) e, com isso, pudemos perceber alguns aspectos que envolvem a avaliação da aprendizagem no ensino superior, como também as diferenças e semelhanças com o que ocorre em outros níveis de escolaridade.

Essas aproximações da realidade mostraram como hoje é trabalhada a avaliação no ensino fundamental. Nele, o educador busca que ela seja algo presente no dia-a-dia de sua sala de aula, e, utiliza-se de observações que possibilitam o direcionamento dos conteúdos, bem como a percepção do desenvolvimento de cada aluno. Isso aponta para a importância da clareza na definição dos objetivos educacionais em cada nível de ensino. Segundo Oliveira (2002, p.52), "o objetivo maior da avaliação da aprendizagem é possibilitar ao professor ir ajustando, durante o desenvolvimento do conteúdo estudado, a ajuda pedagógica às dificuldades individuais dos alunos".

Tal procedimento se faz possível devido ao contato diário que o educador do ensino fundamental tem 
com seus alunos. Ao comparar o processo avaliativo hoje utilizado no Ensino Fundamental e a reflexão da prática pedagógica avaliativa de alguns anos atrás, percebemos que ocorreram grandes mudanças nessa prática. As avaliações lembradas são tradicionais, como a cobrança da tabuada que deveria ser "decorada". O professor perguntava e o aluno deveria responder rapidamente (saber "na ponta da língua"), num procedimento no qual não se valorizava os meios pelos quais se alcançava o resultado. O professor, sendo o possuidor do conhecimento, apenas transmitia seu saber ao aluno, o qual não era levado a refletir para melhor entender o tema em questão.

Também foram mencionadas avaliações, às quais foram aplicados valores voltados para "punir" os alunos por algo de que o professor não havia gostado. Ainda, nas correções das provas escritas ou orais (avaliação tradicional), a impressão que os professores passavam era de que não havia uma preocupação se o que estava sendo respondido estava correto ou se era um pensamento coerente, mas sim se a resposta estava igual à do material estudado. Entendemos hoje que isto não poderia ser visto como uma avaliação da aprendizagem do conteúdo, mas um simples treino de memória.

\section{Informações colhidas junto a professores de Ensino Médio e de licenciaturas}

Buscamos aproximar-nos do que ocorre no ensino médio (magistério), para verificar os procedimentos/ instrumentos avaliativos por eles vivenciados, através de um questionário. Apesar das dificuldades para a coleta do questionário junto aos professores, em suas respostas podemos verificar que são vários os instrumentos/procedimentos utilizados para a avaliação, e muitos deles visam à formação do professor, dos quais podemos citar, como respostas em comum, a apresentação de trabalhos e seminários, e como respostas diferentes, a participação em sala de aula, simulação de aulas e trabalhos manuais.

Nesse nível de ensino, algumas avaliações mudaram, deixando de ser tão tradicionais quanto à do Ensino Fundamental, o que pode ser entendido como sendo conseqüência de uma visão mais ampliada do educador. Nas informações referentes às avaliações praticadas no Ensino Médio, mostraram-se presentes atividades em grupo, nas quais várias visões do mesmo problema eram abordadas para chegar aos resultados, instigando o aluno a refletir, o que lhe possibilitava entender melhor o conteúdo.

Em Vasconcellos (2001), como também na reflexão do processo avaliativo, percebemos que são vários os instrumentos/procedimentos avaliativos que vêm sendo utilizados no ensino superior, sendo esses positivos e negativos para a formação do docente. Nos procedimentos/instrumentos avaliativos negativos, podemos encontrar, entre outros, os que visam apenas à reprodução do conhecimento, não sendo necessário ao aluno o uso do raciocínio, como o que é solicitado pelas provas objetivas. E nesses casos, "O aluno não se conforma com uma avaliação que o domina e o priva do exercício de pensar, já que muitas vezes refere-se ao fato de que só lhe cobram memorizações". (VASCONCELLOS, 2001, p.176).

Para evitar procedimentos avaliativos mal elaborados, é necessário ao educador estar sempre atualizado, mantendo uma formação continuada. A esse respeito, Berbel (2001, p.66) fala da [...] necessidade de aprendizado e aperfeiçoamento contínuo do professor em relação ao aspecto políticopedagógico da sua atuação com seus alunos em que a definição de critérios claros para a avaliação se faça presente.

Vários instrumentos/procedimentos foram citados como positivos pelos professores consultados, e a maioria visa ao preparo do aluno para sua atuação profissional. Isso pode ser percebido pela fala de um dos professores do ensino fundamental:

Achei mais interessante e mais condizente as avaliações nas quais podíamos nos expressar, em conversas, pesquisas e seminários. Desta forma, poderíamos exercitar a oralidade, inter-relacionando com o conteúdo; e também o retorno do professor, com críticas positivas e apontando os erros. (P2). 
Vasconcellos (2001) encontra nos pontos positivos e negativos da avaliação, a questão da competência técnica e do comprometimento do educador. $\mathrm{O}$ profissional docente com competência técnica é aquele que atinge os objetivos maiores da educação.

Confrontando a análise dos resultados com a literatura sobre os procedimentos/instrumentos que estão ocorrendo no ensino superior, podemos perceber que são poucas as diferenças existentes nas avaliações do ensino médio quando comparadas com o ensino superior, nos quais são realizadas avaliações como forma de premiação, de aplicação do autoritarismo, de verificação, de seleção, de classificação etc...

Hoffmann (1996, p.4) reforça essa preocupação, mostrando que:

\begin{abstract}
A história da avaliação educacional é constituída por um forte reprodutivismo. As mesmas práticas se repetem há um século e as tentativas de uma reflexão sobre elas são obstaculizadas por posturas comportamentalistas que colocam a culpa do fracasso em maus professores / expositores e em desatentos alunos/ouvintes por condições sociais e materiais que independem da escola.
\end{abstract}

Muitas avaliações ainda hoje se mostram conservadoras, apresentando objetivos distorcidos como memorizar conteúdos, visar especialmente à nota entre outros. Isso revela que seus aplicadores não percebem a avaliação como parte integrante do processo ensino-aprendizagem. Esse fato é verificado no ensino superior, na formação de educadores, no qual os objetivos devem permear uma avaliação reflexiva, que permita a tomada de consciência acerca de determinados problemas.

Dependendo da formação pedagógica do professor, seu desempenho é mais ou menos consciente, informado, atualizado e conseqüentemente mais ou menos adequado ao que a educação superior hoje requer desses profissionais (BERBEL, 2001, p.7).

Sendo assim, parece não existir uma forma de avaliação definida para o ensino superior nas licenciaturas. Considerando a especificidade dos objetivos para o nível de ensino superior, e considerando as informações apresentadas anteriormente, formulamos, para continuidade dessa pesquisa, o seguinte problema: O que há de específico, na avaliação da aprendizagem, para o Ensino Superior?

Este estudo tem relevância para os alunos e educadores deste nível de ensino, os quais, em contato com o material produzido, poderão indagar-se acerca do que está acontecendo em sua realidade, como os meios avaliativos estão sendo realizados e no que isso poderia ser melhorado. Tal reflexão se faz necessária não só aos responsáveis pela formação de professores, mas aos futuros docentes, para que não estejam apenas reproduzindo o que aprenderam, mas avaliando seus alunos de maneira condizente com o nível de escolaridade dos mesmos.

\section{Pontos-Chave}

Nesta etapa da Metodologia da Problematização, realizamos o levantamento dos pontos-chave, cuja elaboração ocorre a partir de uma reflexão, análise e definição de alguns aspectos que envolvem o problema identificado. Por meio da discussão dos possíveis fatores e dos condicionantes maiores associados ao problema é que definimos o caminho e o conteúdo como orientação para a etapa seguinte.

\section{Reflexão sobre o problema}

Sabemos que muitos fatores podem estar associados às dificuldades de elaborar uma avaliação específica para a formação docente em nível superior, também, percebemos a necessidade de haver objetivo, reflexão, inovação e comprometimento para a aplicação de todo instrumento avaliativo.

Face a essas considerações, indagamos: Quais os objetivos que envolvem a avaliação na formação de professores? Está havendo, por parte do docente, uma reflexão da ação pedagógica na prática avaliativa? As formas avaliativas que vêm ocorrendo são apenas uma reprodução das formas aplicadas no ensino médio? Essas indagações deixam em 
dúvida o comprometimento de muitos educadores e de como se processou sua formação.

Muitas vezes percebemos que os objetivos para a aplicação dos procedimentos/instrumentos avaliativos nas licenciaturas não são claros, o que acaba permitindo o uso da avaliação de forma indevida. Outro agravante dessa realidade é a falta de reflexão sobre a ação pedagógica executada.

Professores, em geral, parecem realizar ações sem analisá-las criticamente, pois o que se percebe num primeiro olhar sobre a avaliação no ensino superior é a repetição do que ocorre nos outros níveis de ensino. Esse fato pode ocorrer por vários motivos, entre eles, a ausência de reflexão pelo professor, por falta de tempo, de costume ou mesmo de percepção do que vem ocorrendo na sua ação. $\mathrm{O}$ comodismo e conservadorismo em face dos instrumentos / procedimentos é outro fator pelo qual o educador aceita a situação em que se encontra, aplicando suas avaliações de forma repetida, sem inovar.

Como determinante maior do problema em estudo, pensamos que as exigências referentes aos aspectos administrativos da avaliação feita pela Instituição de Ensino não têm contribuído para a melhoria da elaboração de avaliações pelo professor. Outro determinante maior pode estar nas condições de preparo do professor para essa elaboração e para a reflexão de sua ação.

As questões éticas também estão presentes na atuação docente (VASCONCELLOS, 2001), e têmse mostrado como um motivo para fugir dos objetivos reais da prática avaliativa, pois alguns professores têm dificuldades de separar o pessoal do profissional. Os valores e crenças adquiridos durante a formação docente estão presentes na ação do educador e podem interferir (ou não) no desejo de mudanças.

Levando em consideração os pressupostos acima mencionados, definimos os seguintes pontos-chave para a investigação:

- Os objetivos pretendidos para a formação no Ensino Superior (licenciaturas), conforme a literatura.

- Modalidades avaliativas existentes na literatura.

- As exigências da Instituição de Ensino Superior quanto à avaliação.

- As avaliações praticadas nas licenciaturas da UEL.
Com esses aspectos, pensamos obter subsídios mínimos para encaminhar respostas ao nosso problema de pesquisa.

\section{Teorização}

$\mathrm{Na}$ terceira etapa, procuramos descrever a investigação que realizamos acerca dos pontos-chave definidos, procurando entender melhor o tema de nosso estudo. Iniciamos, assim, pelos objetivos da formação nos cursos de licenciatura, e passamos às exigências formais da Instituição e as avaliações praticadas nas licenciaturas da UEL. Com isso, buscamos compreender melhor a realidade existente com o intuito de nos prepararmos para nela atuar.

\section{Os objetivos pretendidos para a formação no Ensino Superior (licenciaturas), conforme a literatura}

É importante conhecer os objetivos pretendidos para a formação docente, pois acreditamos que se faz necessário a clareza dos mesmos para aplicar avaliações no ensino superior. Godoy (1995) acredita que "dependendo dos objetivos pretendidos para a aprendizagem, nesse caso a formação de professores, é que será definido o tipo de avaliação a ser aplicada".

Ainda neste sentido, Perrenoud (2000) percebia como objetivo primordial da preparação do Educador, a inserção deste em um contexto educacional baseado na prática política e na formação da consciência, tendo por referencial a prática educativa em sua relação com a prática política. Ao educador, não cabe isolar os acontecimentos que o rodeiam, mas apresentá-los em sua ação, sempre política, mostrando as várias formas de percebê-los. Com isso, o educador terá sua expressão maior na consciência política.

A LDB n 9.394, de 20 de dezembro de 1996, no Art. 43, traz para a educação superior a finalidade de estimular a criação cultural, o desenvolvimento do espírito cientifico e do pensamento reflexivo, bem como a promoção do desejo de aperfeiçoamento, por meio da integração entre os conhecimentos 
adquiridos. Nessa perspectiva, o ensino superior estará formando um educador mais autônomo e crítico, o qual procura estar em constante formação.

Em uma mesma perspectiva, nas Diretrizes para a formação de professores, encontramos como objetivos a aquisição das competências e a apropriação de determinados conteúdos necessários para os futuros professores. Com eles, o educador será mais independente para usar suas capacidades na atuação profissional.

Assim, percebemos que os objetivos educacionais pretendidos para a formação de professores estão diretamente relacionados com as competências, as quais indicam o que é necessário para o exercício da prática docente. A avaliação deverá oportunizar ao futuro educador, situações nas quais ele possa criar, planejar, realizar, gerir e avaliar. A elaboração e o desenvolvimento de projetos é um instrumento avaliativo que poderá ser utilizado na educação superior para que o futuro educador possa se preparar para gerenciar o próprio desenvolvimento profissional.

Nesse sentido, reforçamos que cabe aos cursos de licenciatura preparar avaliações que visem à formação, com base nos objetivos propostos, em cada caso e à luz das diretrizes para a formação de professores no Ensino Superior.

\section{Modalidades avaliativas existentes na literatura}

A avaliação é reconhecida atualmente como um dos pontos privilegiados para averiguar o processo de aprendizagem. Discutir o problema da avaliação supõe, necessariamente, questionar os problemas fundamentais da pedagogia. Lembremos, a esse respeito, que a avaliação é um processo concernente à existência humana e implica uma reflexão crítica sobre a prática. Com isso, busca-se captar seus avanços, suas resistências, suas dificuldades e possibilitar uma tomada de decisão sobre o que fazer para superar os problemas identificados (DIAS SOBRINHO, 2000).

Buscando uma prática avaliativa específica ao Ensino Superior, percebemos a necessidade de conhecer as modalidades existentes, com o intuito de encontrar a que melhor se adapte aos objetivos desse nível de ensino. Num sistema educacional, a avaliação objetiva determinar o nível de eficiência e eficácia com que os objetivos ou resultados são alcançados, não representando um julgamento, mas um processo que permite o julgamento, oferecendo informações úteis para a tomada de decisões (OLIVEIRA, 2002).

Para que a avaliação possa ser feita satisfatoriamente, é necessário que seja realizada no início, no decorrer e no fim do processo ensinoaprendizagem. Não há um só tipo de avaliação a respeito do qual exista consenso, pois quando falamos de avaliação, com certeza não estamos fazendo referência sempre à mesma coisa. Sendo assim, dentre as modalidades avaliativas existentes, Bloom, Hastings e Madaus (1983) consideram importantes: a avaliação diagnóstica, a formativa e a avaliação somativa.

A modalidade avaliativa diagnóstica tem como função básica determinar a presença ou a ausência de habilidades ou pré-requisitos, indicar as causas de dificuldades na aprendizagem e agrupar os alunos de acordo com características comuns e, com eles, desenvolver um tipo de ensino (MIRAS; SOLÉ, 1996). Ela é aplicada no início do curso, com o objetivo de verificar se os discentes detêm ou não os pré-requisitos exigidos para a aprendizagem, buscando recuperar os conteúdos ainda não apreendidos pelos alunos e verificar o nível de aquisição de certo conhecimento.

Essa modalidade também pode ser realizada quando o professor se deparar com problemas de aprendizagem de seu aluno, durante o ano letivo. Com ela, busca-se conhecer as possíveis causas, assim ela é realizada por meio de testes que possibilitam diagnosticar as condições em que o aluno se encontra frente os objetivos a serem atingidos (MIRAS; SOLÉ, 1996).

A avaliação formativa, outra das modalidades aqui salientadas, respeita a individualidade e busca a regulação da aprendizagem. Aparece, então, como um componente necessário para a diferenciação das intervenções e dos meios pedagógicos, e mesmo dos 
passos de aprendizagem ou dos ritmos de progressão, ou, ainda, dos próprios objetivos (PERRENOUD, 2000). Para o autor, essa modalidade fundamentase nos progressos de aprendizagem, em seus aspectos cognitivos, afetivos e relacionais, contribuindo para que o estudante organize melhor o seu estudo, permitindo um planejamento eficaz da sua aprendizagem. Deve ser utilizada como instrumento de controle no decorrer de todo o ano letivo, com o objetivo de certificar-se se os educandos estão ou não atingindo os objetivos pré-estabelecidos. O professor, nesta avaliação, não faz mais a tão comum seleção ao dar nota aos alunos, mas acredita na constante relação pedagógica. Neste sentido, avaliação formativa é o nome dado à ação que avalia o aluno sob o aspecto de sua formação intelectual e humana, e tem a função de informar como está ocorrendo a aprendizagem.

Haydt (1995) nos coloca que a avaliação formativa está ligada ao mecanismo de "feedback". Este, quando relacionado com a avaliação, permite que o ensino possa ser reformulado e reconstruído. No Ensino Superior, a avaliação formativa poderá ser aplicada de forma que os próprios alunos, por meio do "feedback", da auto-avaliação e da autocorreção, percebam seus erros/dificuldades, assim como seus sucessos. Sendo assim, o aluno poderá direcionar seus estudos visando a obtenção dos objetivos pretendidos para a sua educação. Dessa forma, o aluno terá a oportunidade de controlar e avaliar seu processo de aprendizagem.

A terceira modalidade aqui apresentada é a avaliação somativa, que tem como preocupação verificar as consequiências da instrução, por meio do fornecimento de dados relativos ao rendimento total da aprendizagem. Embora a avaliação somativa envolva um período mais longo de ensino, não há fronteiras nítidas entre ela e a avaliação formativa (MIRAS; SOLÉ, 1996). A avaliação somativa de um período pode servir de avaliação formativa para o período seguinte. Mesmo contendo algumas diferenciações, é importante trabalhar paralelamente essas duas modalidades. Haydt (1995, p.19) reforça esta idéia dizendo:
Essas três formas de avaliação estão intimamente vinculadas. Para garantir a eficiência do sistema de avaliação e a eficácia do processo ensino aprendizagem, e o professor deve fazer uso conjugado das três modalidades.

A principal função da avaliação somativa é classificar o aluno e essa classificação deve estar de acordo com o pré-estabelecimento dos níveis de aproveitamento, definidos com o objetivo de promover o aluno para outra série (MIRAS; SOLÉ, 1996).

Há também a avaliação classificatória, na qual as técnicas utilizadas proporcionam instrumentos de controle (provas surpresa, seleção de alunos em determinadas turmas de acordo com o rendimento). Em geral, a aprendizagem é confundida com memorização de um conjunto de conteúdos desarticulados, conseguida através de repetição de exercícios sistemáticos de fixação e cópia. Existe o estímulo de reforço positivo e negativo (recompensas, castigos). A aula é expositiva e a verificação da aprendizagem se dá por meio de periódicas avaliações vistas como instrumentos de controle e de checagem da necessidade de reformulação das técnicas empregadas (GANDIN, 1995).

Gandin ainda ressalta que esse tipo de avaliação na escola torna-se um instrumento de controle, já que ela consiste na verificação de um produto ou uma ação, efetuada com base num padrão estabelecido anteriormente. Ela se refere à eficiência, istoé, a busca saber se algo foi realizado como deveria ser realizado. Para o autor, a avaliação classificatória, ao dar ênfase ao aprovar ou reprovar o aluno, mostra uma face cruel da escola, aquela que exclui muitos alunos do acesso ao saber. Além disso, ela tira da prática avaliativa algo essencial: a reflexão acerca do fazer pedagógico, redirecionando a ação rumo ao desenvolvimento do aluno.

Outro paradigma usado como modalidade avaliativa é a avaliação emancipatória, que se caracteriza como um processo de descrição, análise e crítica de uma dada realidade, visando a transformá-la. Destina-se à avaliação de programas educacionais ou sociais. Ela está situada numa vertente político-pedagógica, cujo interesse primordial 
é emancipador, ou seja, libertador, visando a provocar a crítica, de modo a libertar o sujeito de condicionamentos deterministas. O compromisso principal dessa avaliação é fazer com que as pessoas, direta ou indiretamente envolvidas em uma ação educacional, escrevam a sua "própria história" e gerem as suas próprias alternativas de ação (SAUL, 2000).

A avaliação mediadora vem servir como intervenção entre educadores e educandos. Sua essencialidade é conhecer melhor o educando, entender suas falas, seus argumentos, conversar com ele em todos os momentos, ouvindo todas as suas perguntas, fazendo-lhes novas e desafiadoras questões, implicantes, até, na busca de alternativas para uma ação educativa voltada para a autonomia moral e intelectual (HOFFMANN, 2002). Assim, uma ação educativa voltada à autonomia é necessária, à medida que se inicia com a criança e contempla $\mathrm{o}$ jovem e o adulto, oferecendo a eles condições de se tornarem fortes e resistentes. E quando se fala do respeito à 'autonomia do educando', Freire (1996, p.66) assim esclarece:

Como educador, devo estar constantemente advertido com relação a este respeito que implica igualmente o que devo ter por mim mesmo. Não faz mal repetir a afirmação várias vezes feita neste texto - o inacabamento de que nos tornamos conscientes nos fez seres éticos. O respeito à autonomia e à dignidade de cada um é um imperativo ético e não um favor que podemos ou não conceder uns aos outros.

O educador, ao lidar com a avaliação da aprendizagem escolar, deve ter em mente a necessidade de colocar em sua prática diária novas propostas que visem à melhoria do ensino, pois a avaliação é parte de um processo e não um fim em si mesma, e deve ser utilizada como um instrumento, também para a melhoria da aprendizagem dos educandos.

\section{As exigências da Instituição de Ensino Superior quanto à avaliação}

É importante refletir acerca das exigências de um sistema de avaliação da educação superior que envolva todas as dimensões inseridas da Universidade diante do compromisso com a demanda social. Com efeito, essa discussão vem ganhando importantes espaços, principalmente se associada às necessidades de construção de uma nova e melhor universidade e passível de fazer frente às exigências para a educação superior. Nesse sentido, procuraremos discutir as exigências de avaliação das instituições de ensino superior, enfocando em seguida a Universidade Estadual de Londrina (UEL).

Para tal, consultamos a literatura a respeito de avaliação institucional para a educação superior, com a finalidade de obter embasamento para entender a avaliação da aprendizagem. É importante ressaltar que a avaliação institucional é um processo imerso em aspectos ideológicos, políticos, econômicos, culturais, dentre outros, e tem como indicadores a vocação, a política de seleção, a inserção social e o compromisso com a justiça. Ela representa um empreendimento que tem por objetivo melhorar a universidade por meio da tomada de consciência acerca da instituição (BELONI, 1980).

A avaliação é um instrumento fundamental para todo organismo social que busque desenvolvimento e qualidade. Para a universidade, instituição cuja razão de ser encontra-se na prestação de serviços de qualidade à sociedade, buscando sempre a excelência na produção, sistematização e democratização do saber, o propósito da avaliação institucional deve ser o de conduzir ao aperfeiçoamento constante dos empreendimentos humanos (BELONI, 1980).

Outro objetivo fundamental da avaliação institucional explicita a natureza do processo que é a necessidade de potencializar e desenvolver as pessoas da instituição e, conseqüentemente a própria instituição. De acordo com essa perspectiva, a avaliação passa a ser compreendida como mecanismo de produção, desenvolvimento científico e de juízo de valor sobre a universidade, o processo avaliativo, as relações humanas institucionalizadas, dentre outros aspectos (COÊLHO, 1997). Ao tratar do tema, o autor ainda comenta que a avaliação institucional de uma universidade sempre deverá 
relativizar as inter-relações existentes nos processos acadêmicos. No entanto, terá também que avaliar o atendimento às expectativas da sociedade na qual está inserida, sem perder de vista suas funções de ensino, pesquisa e extensão. Mas, para constituir um poderoso instrumento de prestação de contas à sociedade, é preciso introduzir mudanças que melhore a qualidade das atividades na universidade como processo de aperfeiçoamento institucional.

Luckesi (2000) discute a questão da avaliação da aprendizagem e explicita que:

Importa estarmos cientes de que a avaliação educacional, em geral, e a avaliação da aprendizagem, em particular, são meios e não fins em si mesmas, estando assim delimitadas pela teoria e prática que as circunstancializam. Desse modo, entendemos que a avaliação não se dá nem se dará num vazio conceitual, mas sim dimensionada por um modelo teórico de mundo e de educação, traduzido em prática pedagógica.

Nessa perspectiva, a prática da avaliação não pode ser feita simplesmente de forma medida, calculada, impressa por um valor numérico. Ela precisa estar ressarcida de valores construídos pelos homens, buscando um projeto maior de sociedade que atenda os interesses de toda a população. Então, avaliar o aluno requer muito mais, exige muito mais.

A prática de avaliação da aprendizagem que vem sendo desenvolvida nas nossas instituições de ensino superior nos remete a uma posição de poucos avanços. Porém, a avaliação é um ato dinâmico no qual o professor e o aluno podem assumir o seu papel, de modo co-participativo, por meio da implementação do diálogo e da interação respeitosa, comprometendo-se com a construção do conhecimento e a formação de um profissional competente (SORDI, 1995).

Os mecanismos avaliativos devem pretender verificar, principalmente, a qualidade do processo de ensino-aprendizagem, revelando dificuldades, carências e inquietações dos alunos e reorientando o trabalho do professor, na superação dos fatores limitativos da plenitude possível na aprendizagem (HAYDT, 1995). No entanto, o que se percebe mais constantemente na avaliação dos estudantes do ensino superior, nos dias atuais, é uma valorização excessiva do aspecto quantitativo, em detrimento da verificação da qualidade do que é ensinado e aprendido.

A avaliação também pode ser considerada, para Bloom, Hasting e Madaus (1983), um instrumento da prática educacional para verificar se procedimentos alternativos são ou não igualmente efetivos ao alcance de um conjunto de fins educacionais. Essa prática envolve uma coleta sistemática de dados, por meio dos quais se determinam as mudanças que ocorreram no comportamento do aluno, em função dos objetivos educacionais e em que medida estas mudanças ocorreram.

O mito da avaliação da aprendizagem é decorrente de sua caminhada histórica e seus fantasmas ainda se apresentam como forma de controle e de autoritarismo por diversas gerações.

\section{$O$ sistema de avaliação na UEL}

Os métodos de avaliação ocupam, sem dúvida, um espaço relevante no conjunto das práticas pedagógicas aplicadas aos processos de ensino e aprendizagem. Na universidade, tal relevância assume proporções ainda mais críticas, pois se aguarda o homem culto, o profissional competente, enfim, o indivíduo capacitado à resolução de problemas referentes a uma ou mais áreas de conhecimento.

A avaliação do aproveitamento escolar nos cursos da Universidade Estadual de Londrina, conforme dispõe o Regimento Geral, é feita por disciplina, por meio da realização de provas, atividades acadêmicas obrigatórias e atividades acadêmicas complementares, e da utilização de diversas técnicas e instrumentos estabelecidos nos Projetos PolíticosPedagógicos específicos. A avaliação do aluno, realizada pelo professor, é expressa por meio de notas de 0 (zero) a 10 (dez). Ao final de cada período letivo é atribuída ao aluno, em cada disciplina regularmente cursada, uma nota final, resultante da média de no mínimo 02 (duas) avaliações realizadas durante o período / semestre letivo, independente da carga horária da mesma. 
São obrigatórias, no mínimo duas avaliações de aprendizagem, por disciplina, em cada período, e o sistema de avaliação, parte integrante do projeto político-pedagógico de cada curso, é estabelecido pelo respectivo Colegiado, antes do início do ano letivo, como mostra no Art. $5^{\circ}$, Segundo parágrafo do Regulamento Geral (2004):

$\S 2^{\circ}$ As formas de avaliação das disciplinas devem ser aprovadas pelo Colegiado e comunicadas à Coordenadoria de Ensino de Graduação PROGRAD, através dos planos de cursos.

A forma de avaliação de cada disciplina e das atividades acadêmicas obrigatórias deve atender aos objetivos do projeto político-pedagógico do curso. As atividades acadêmicas obrigatórias terão sistema de avaliação definido em regulamentos próprios, aprovados pelo Conselho de Ensino, Pesquisa e Extensão e informados no plano de curso específico encaminhados à PROGRAD.

Conforme o Art. $6^{\circ}$, os docentes devem dar conhecimento aos alunos dos resultados das avaliações de aprendizagem no prazo de 30 (trinta) dias após a realização das mesmas.

$\S 2^{\circ}$ Os resultados das verificações de aprendizagem devem ser amplamente discutidos entre professores e alunos, assegurando-se, desse modo, o acesso à prova ou trabalho corrigido.

É promovido para a série subseqüente o aluno aprovado em todas as disciplinas da(s) série(s) anterior (es), reprovado por nota ou por falta, em até 2 (duas) disciplinas da(s) série(s) anterior(es). No momento em que se registra em forma de nota o resultado obtido pelo aluno, é fragmentado o processo de avaliação e introduzida uma burocratização que leva a se perder o sentido do processo e da dinâmica da aprendizagem. Como a avaliação tem reconhecidamente uma função diretiva, ou seja, tem a capacidade de estabelecer a direção do processo de aprendizagem, oriunda essa capacidade de sua característica pragmática, a fragmentação e a burocratização acima mencionadas levam à perda da dinamicidade do processo (DIAS SOBRINHO, 2000).
Seguindo este propósito, os dados registrados são resultados formais e não representam a realidade da aprendizagem, embora apresentem consequiências importantes na vida pessoal do aluno. Entende-se que, nos documentos da UEL, a avaliação representa antes uma classificação do que para a investigação. Em seu regimento, o Art.56, que trata de avaliação, está intitulado como Sistema de Aprovação da Graduação, ou seja, caracterizando maior preocupação com a aprovação do que com a aprendizagem.

Nesse sentido, consta dos documentos do Regimento Geral que o sistema de avaliação da aprendizagem da UEL é feito de forma a classificar o aluno em um certo estágio de desenvolvimento. Porém, não há como negar que, algumas disciplinas da UEL utilizam critérios para avaliação estabelecidos somente pelos professores, reforçando, assim, o processo de aprendizagem e autonomia dos alunos.

Contudo, a avaliação nas mãos de alguns professores torna-se um instrumento disciplinador de condutas sociais, pois eles a utilizam como critério para aprovação dos alunos, e buscam controlá-los e discipliná-los. Com isso, retira-se deles a espontaneidade, criticidade e criatividade, e eles transformam-se em "cordeiros" de um sistema autoritário e antipedagógico. Nessa linha de raciocínio, ao refletirmos sobre a condução do processo de avaliação, surgem alguns questionamentos: Os professores sabem avaliar? Qual o objetivo do processo de avaliação?

As avaliações praticadas nas licenciaturas da UEL

Neste ponto, analisaremos as entrevistas feitas com os docentes de Licenciatura da UEL, de diferentes cursos. Estes docentes não são identificados, sendo nomeados com letras e números. Em função dos objetivos da presente pesquisa, que salienta as práticas dos docentes referentes aos vários aspectos envolvidos no processo de avaliação da aprendizagem, buscaremos, na literatura especializada, os estudos que examinam a avaliação a partir da análise deste processo. Pelos depoimentos, 
é possível detectar que os professores não discordam da avaliação em si - apontando-a como necessária e válida.

Ao analisar as entrevistas, percebemos que muitos professores utilizam variadas formas para avaliar o aluno, tais como prova oral e escrita, trabalhos com obra de arte, avaliação com filmagens, construção de artigos, participação do aluno considerando o ponto de vista de cada um, seminários, discussão, auto-avaliação escrita e oral, entre outras. Estas ações nos lembram Vasconcellos (1998), ao afirmar que o maior desafio do docente é utilizar a avaliação como recurso metodológico de reorientação do processo ensino-aprendizagem, sem que a nota seja o único e principal objetivo da relação pedagógica. Podemos observar esta prática na fala de um professor:

Eu trabalho com prova oral, prova escrita, com seminário, com discussão, com auto-avaliação escrita e oral. A diversidade para mim é muito importante, e a possibilidade do aluno discutir sua própria avaliação. Ele não fica preso à nota, à classificação, ainda que tenhamos que dar conta de uma nota (C2).

Bloom, Hastings e Madaus (1983) afirmam que os procedimentos de avaliação ocorrem durante toda a instrução educativa. Segundo os autores, a variedade de dados auxilia o esclarecimento de metas e objetivos educacionais necessários para acompanhar e verificar se o processo de ensinoaprendizagem está ocorrendo conforme o previsto.

Os professores que praticam essas variadas formas de avaliar, acreditam que assim vão preparar o licenciando para o seu campo profissional, principalmente situando-o dentro desse contexto. Nas falas dos professores, notamos que os mesmos diversificam as formas de avaliar, para que assim existam oportunidades aos alunos, principalmente para aqueles alunos que são tímidos ou vão mal em seminários, podendo se sair melhor em outra forma de avaliação ou vice-versa.

Às vezes você percebe que o aluno entendeu o conteúdo, mas não sabe expressar isso de forma escrita, por isso precisamos possibilitar a ele uma expressão diferente do conteúdo, porque nós temos que lidar com a dificuldade que eles têm na habilidade de interpretação, porque muitos são tímidos, na habilidade de escrita, de leitura, que são dificuldades que eles trazem do ensino médio (F5).

Um ponto importante a ser explicitado das entrevistas é aquele em que o professor diz que o aluno precisa ter várias tarefas de curto prazo com avaliação, mesmo que não valha nota, só para avaliar, desafiar e ali ser corrigido no que errou, ser fortalecido no que acertou, de forma pública, de modo que todos possam aproveitar uns dos outros o que acertaram e o que erraram.

$\mathrm{O}$ professor $\mathrm{C} 4$ acredita que o aluno, quando tem essas avaliações freqüentes, fica sabendo se está aproveitando, se está progredindo e em tempo, para ir corrigindo. Acredita que o aluno tem que passar por várias avaliações sem nota, por que o objetivo é fazê-lo aprender o conteúdo, aprender a não ter medo de errar, porque são corrigidos e isso não tem conseqüência nenhuma quanto à nota.

$\mathrm{O}$ aluno precisa ter tarefas de curto prazo, com avaliação, mesmo que não valha nota, só para avaliar, desafiar e ali ser corrigido no que errou [...] e ser fortalecido no que acertou quando tem essas avaliações freqüentes, fica sabendo se está aproveitando, se está progredindo e em tempo, está corrigindo (C4).

Essa prática avaliativa faz-nos lembrar a avaliação formativa, sendo nesta modalidade que melhor se acompanha o processo do aluno. Para Bloom, Hastings e Madaus (1983), a avaliação formativa:

Refere-se à avaliação da aprendizagem de um aluno durante um curso, quando podem ser efetuadas mudanças na instrução subseqüente, a partir dos resultados atuais. Seu maior mérito está na ajuda que ela pode dar ao aluno em relação à aprendizagem da matéria e dos comportamentos, em cada unidade de aprendizagem.

Dentre os itens de práticas avaliativas, uma sempre mencionada é a elaboração de seminários para serem apresentados em sala de aula. Um dos docentes (L2) cita o fato de que os seminários servem 
para a socialização de informações, pois cada grupo trabalha com temas diferentes e finaliza com uma síntese do que foi trabalhado para toda a sala. Outro (L3) menciona que, "por meio dos seminários, podese manter um contato direto com os outros alunos e realizar uma discussão com troca de informações". Alguns professores orientam os alunos no sentido de eles terem que fazer articulações dos textos estudados para os seminários que irão realizar, procurando não tratar do tema isoladamente, mas dar continuidade aos conteúdos já trabalhados.

Os seminários implicam discussão do grupo acerca do assunto pesquisado, aprofundamento teórico, estudo dirigido e exposição oral, além de exigirem do aluno a capacidade de sintetizar conhecimento (OLIVEIRA, 2001). Outra intenção de aplicar seminários "é fazer com que os alunos percam o medo de se comunicar em público" e dominar a atenção. $\mathrm{O}$ professor I2 ainda esclarece que "os seminários estimulam o esclarecimento e o amadurecimento" ao ter este contato com a turma:

Os seminários têm a intenção que eles tenham o momento de seu envolvimento, de já ter uma experiência de ir para a lousa, de usar recursos audiovisuais, dominar a atenção da sala de aula, pois eles são licenciandos [...] e eles estão sendo formados professores, desde o primeiro ano (I2).

Para I2, é por meio do diálogo existente nos seminários que o professor acompanha o aluno na construção do conhecimento. Outro professor (L3) ainda completa, dizendo que é importante que o aluno participe, dialogue com a sala e com o professor, e que eles não realizem os seminários somente pela nota, mas porque aquilo lhes é relevante. Para este docente "ninguém está ali para reprovar".

Há também um outro tipo de aplicação de seminários, porém de uma forma diferente. $\mathrm{O}$ professor M2 divide a sala em cinco grupos e cada grupo faz um seminário de um assunto e um relatório do seminário. Esse relatório deve ser apresentado nos moldes de uma revista científica:

Não é um relatório como muitos professores fazem, tem que ter um certo rigor científico, que é para firmar na cabeça deles para quando eles forem fazer pesquisa (M2).
No dia do seminário, o professor estabelece as regras de que será apresentado por um único aluno e esse aluno irá ser sorteado no momento da apresentação. Com isso todos os integrantes do grupo têm de se preparar, pois na apresentação só o que está apresentando é que será avaliado.

Dentro do corpo docente entrevistado, há o que costuma interferir nas apresentações (L2), levantando questionamentos para a sala e para o grupo em questão. Por conta disto, diz a docente que aplicar seminário fica mais cansativo do que dar aula, porque tem que ficar atenta ao que o aluno está falando, pois ela corrige, interrompe qualquer conceito errado: Eu não gosto de dar seminário e pronto, gosto de participar também (L2).

Esta prática é considerada uma ação importante, pois assim a professora complementa o seminário. Encontramos nas entrevistas uma prática semelhante a essa, porém o retorno é encaminhado ao aluno pósapresentação e pós-realização de provas ou trabalhos, conhecido como feedback. Muitos dos professores entrevistados (A1, B2, C2, C3, C4, H1, H2, J1, L1, L2, L4, M3) utilizam feedback para seus alunos, pois estes docentes aplicam a prova, corrigem, conversam, as entregam com anotações e dão um prazo para que os alunos (as) refaçam e devolvam. Fazendo isso constantemente, pode-se perceber se o aluno está crescendo, e a informação dada ao estudante a respeito da qualidade do seu desempenho é fundamental.

Encontramos em Berbel (2001) que o feedback é uma das ações mais importantes do professor em relação à avaliação, pois informa aos seus alunos os resultados que atingiram nas atividades utilizadas para verificar seu aprendizado. Outro exemplo de feedback digno de nota é o procedimento utilizado por um docente (H1), de enviar para seus alunos anotações em forma de carta, com os resultados da avaliação.

Com os resultados da avaliação, por exemplo, eu faço anotações e devolvo sob a forma de cartas. Assim, eu acabo dando várias chances a eles (H1). 
O feedback é importante para ambos (aluno e professor), porque dá ao professor controle da aprendizagem e fornece ao aluno conhecimento de seu crescimento. Mas este feedback precisa ser efetivo e no momento adequado, pois em uma pesquisa sobre o tema, Brito (1984) concluiu que os estudantes, ao receberem feedback imediato acerca do seu desempenho, beneficiam-se mais dos cursos realizados.

$\mathrm{O}$ uso de feedback imediato está relacionado, de forma clara e positiva, à satisfação e o rendimento dos alunos. Este feedback pode ser fornecido pelas avaliações diagnósticas do início do semestre, por avaliações intermediárias durante o semestre, assim como pelas avaliações destinadas a verificar a efetividade do curso de graduação como um todo. A manutenção dos efeitos do feedback vai, no entanto, depender da qualidade das avaliações realizadas e da qualidade do próprio feedback.

Assim, para Brito (1984), apontar as fontes de erros propiciando esclarecimentos e encorajando os alunos, constitui um feedback mais efetivo do que simplesmente informá-los acerca dos resultados obtidos ou fazer comentários genéricos. Nas salas de aula, devem ser propiciadas aos alunos diferentes oportunidades para que eles demonstrem seu desempenho e recebam sugestões para melhorá-lo.

Alguns professores não separam a aprendizagem e a avaliação, pois fazem correlação da teoria com a prática e avaliam tudo o que o aluno produz, até mesmo sua presença, de modo que essa prática se torna completa. $\mathrm{O}$ docente, ao estabelecer essa relação, acredita que a avaliação não seja encarada como cobrança, ao contrário, quer que ela seja vista como situação de aprendizagem. Para que isso ocorra, ele leva os alunos a pesquisar várias outras fontes do mesmo tema, seguido de uma discussão em sala para um melhor entendimento. O objetivo é levá-los à reflexão, pois a aprendizagem não acontece só na sala de aula, mas também na realidade prática.

Algumas atividades enunciadas pelos professores para estabelecer a relação entre teoria e prática são os estágios, discussões teóricas com dinâmica, vivência em laboratório, elaboração de relatórios e resenhas, pesquisas e trabalho de campo.
Dentre os professores entrevistados que utilizam trabalho de campo, há os que se prendem mais à participação do aluno, e não vinculam necessariamente a avaliação à nota, procurando reconhecer o esforço do aluno e se houve investimento de sua parte. O professor investiga se o aluno quis buscar mais conhecimento do que foi trabalhado em sala, e também alterna as discussões teóricas com dinâmicas, para fazer o aluno pensar e conseqüentemente produzir seu conhecimento. Esta ação nos remete a Vasconcellos (1998), segundo o qual a reflexão deve conduzir o indivíduo para a construção de seu conhecimento.

Avaliar a participação do aluno é uma prática constantemente encontrada em várias disciplinas. Este é o caso do docente (H2) que leva a turma de alunos para um trabalho de campo em sua disciplina. Todos os alunos participam do processo de pesquisa e, ao final, é entregue um relatório à prefeitura. Em Berbel (2001), encontramos, nas respostas positivas dos alunos consultados, situações que apontam a importância dos trabalhos de campo, como forma de avaliação. As respostas enfatizam que eles conduzem ao aprendizado e à percepção da validade da teoria trabalhada em relação à realidade, como se pode compreender com mais realismo o aprendido em sala de aula.

Observemos o esclarecimento do professor $\mathrm{H} 2$ :

Eu pensei em muitas atividades onde existe um conceito de participação, não é pela nota. Eu vou anotando a participação deles, não tem prova. Termina sendo natural, a partir do momento em que eles vão ter que dar o retorno daquilo pra comunidade.

$\mathrm{H} 2$ ainda afirma que o trabalho de campo permite aos alunos buscar e produzir conhecimento. Em Vasconcellos (1998), a avaliação tradicional tem raízes profundas no sistema educacional, e o maior desafio do docente é utilizar a avaliação como um recurso metodológico de reorientação do processo de ensino-aprendizagem, sem que a nota seja o principal objetivo da relação pedagógica.

Alguns docentes (L4, L5 e M3) esclarecem que fazem reuniões fora do horário de aula para melhor 
atender seus alunos, dando um respaldo melhor para o desenvolvimento de cada um. Nesses encontros, os professores têm a oportunidade de conhecer melhor seus alunos e até mesmo o motivo de suas dificuldades de aprendizagem, como problemas familiares e outros obstáculos ao desenvolvimento acadêmico. E, com isso, podem estabelecer uma relação de confiança. Assim, o docente sabe até onde o aluno pode ir, pois muitos aspectos envolvem questões pessoais que acabam prejudicando a aprendizagem. Trabalhar e orientar todas as dificuldades que os alunos apresentem, para que estes aprendam o que é necessário, é defendido por Luckesi (2000).

Alguns professores (C1, M1, M2, J4) aplicam provas em dupla, variando em consultar o material ou não, pois o objetivo não é a nota, mas a resposta do aluno. Buscam elaborar uma questão inteligente para que não haja aquela memorização mecânica. Um destes professores (M2) utiliza um procedimento bem interessante. Ele entrega a prova para as duplas responderem, porém essas duplas terão um prazo de 24 horas para devolver a prova. Esse docente afirma o seguinte:

Eu dou uma prova em dupla pra fazer em casa com questões bem amplas e 24 horas para fazer a prova [...] Eu entregava quinta-feira às 5 horas e tinham que me entregar na sexta às 5 . Eles não têm que estudar antes, porque em 24 horas eles têm que apresentar gráficos que não conseguem achar. Para sair procurando as questões com a prova na mão, eles têm que saber a matéria.

Consultar o material não é um empecilho, pois o professor não está interessado em saber se o aluno decorou as definições e sim se ele sabe utilizar o referencial teórico para ler a realidade e elaborar suas respostas. Ele está preocupado se o aluno tem habilidade intelectual para expressar-se. Neste caso, o professor dá importância também à escrita e a capacidade de síntese do aluno, reconhecendo a necessidade de se saber escrever bem e organizar as idéias.

A prova escrita é a forma de avaliação mais utilizada pelos docentes L6 e K2. Na visão de Oliveira (2001), a prova escrita permite economia de tempo, já que os alunos respondem individualmente a mesma questão. Como exemplo, trazemos a resposta de K2:

Pouquíssimas vezes eu dou uma prova objetiva e quando eu dou é trinta ou quarenta por cento da prova o restante é tudo subjetiva. Eu faço questão de que o aluno escreva, saiba colocar se pensamento saiba organizar as idéias.

Avaliar através de filmagens também é uma prática encontrada nas entrevistas de B5, K1 e K2. Há o professor que filma tanto para as provas da parte técnica quanto da parte prática que acontecem dentro da disciplina. Analisando cada aluno diante do vídeo, com tranquiilidade, não na situação de prova, que ficaria muito sujeito a qualquer erro de avaliação, sobre o que devemos ter o maior cuidado. Assim podemos observar na fala de K2:

Então eu poderia estar sentando diante do vídeo e analisando cada aluno com tranqüilidade, não na situação de prova que ficaria muito sujeito a qualquer erro de avaliação que a gente tem que ter o maior cuidado.

Outro docente pede para a turma fazer uma análise de filmes de cunho pedagógico, ou seja, os alunos assistiam a um filme referente à matéria da disciplina e em seguida faziam uma análise para o professor avaliar. Há também um docente (K1) que leciona em uma disciplina que é bem prática, e torna bem viável a gravação das aulas práticas da turma. Ele utiliza três pontos de vista para avaliar: o aluno se auto-avaliando, o professor avaliando o aluno, e um terceiro dando feedback.

Uma forma que pode ser considerada própria do ensino superior é a construção de artigos a serem publicados. Dessa maneira, o docente B2 acredita estar incentivando o aluno e trazendo algo de bom para o meio acadêmico. Vejamos o que afirmou B2:

A prova era para que eles fizessem uma junção do conteúdo, como um "paper" e aqueles alunos que tivessem participado já sabiam que depois teriam que melhorar, colocar em normas para tentar publicação.

Alguns alunos têm de montar uma pasta de estágio contendo todos os assuntos que estudaram. 
No fim do ano, o professor recolhe e faz uma avaliação. Esta pasta, além de servir para consultas posteriores, serviria para fixar a aprendizagem. A pasta de estágio, na visão do docente que a orienta (G1), pode servir também como uma auto-avaliação, por meio da qual os alunos farão críticas e sugestões da metodologia, sendo uma avaliação que envolve tanto o professor quanto a atuação do aluno como futuro professor.

Fazer o aluno expor para a turma atividades que ele já tenha vivenciado, seja de forma escrita, entrevista, ou algum tipo de apresentação oral, afirma o docente F5 ser uma prática positiva de avaliar, porque o aluno tem familiaridade com o assunto tratado, não só com o tipo de atividade, mas com o conteúdo.

Um dos docentes entrevistados (F4), decide junto com a turma qual será a melhor forma de avaliação a ser aplicada. O professor apenas põe duas condições: exposição oral em grupo ou individual, ou avaliação escrita. A turma é que vota e dá o perfil do andamento do curso.

No ensino superior, não há uma só forma específica de avaliar-se o aluno. Ao analisar as entrevistas dos professores de licenciaturas da UEL, verificamos que, de modo geral, a maioria dos professores utilizam diversas práticas avaliativas para avaliar o discente no ensino superior, acompanhandoo e orientando-o no que for necessário. Dentre estas práticas, há aquelas que mais se salientam.

Aplicar seminários e interferir quando necessário para orientar o aluno na sua construção do conhecimento é uma prática que se encontra no ensino superior, pois assim o professor desafia o aluno a refletir sobre as situações, tornando-o mais crítico. Segundo Vianna (1995), situações em que ensino e avaliação estão claramente integrados, com a avaliação ocorrendo durante todo o processo instrucional, contribui, dessa forma, para a aprendizagem. Vianna considera que este é o aspecto que realmente importa quando se fala em avaliação e ressalta que esta integração pode ser conseguida mesmo quando o professor utiliza procedimentos e estratégias mais formais.
Outra prática bastante utilizada pelos professores no ensino superior é a cobrança de construção de artigos a serem publicados. Com esta atividade, os professores incentivam os alunos a participarem mais e mais com produções acadêmicas. Segundo Weber (2003), a educação superior deve ser vista, também, como um espaço que favoreça um sistema construtivo, não só voltado para a transmissão e transferência de conhecimentos.

Realizar atividades que permitam reunir a teoria e a prática, é também uma prática avaliativa bem característica do ensino superior. Confirmando a importância da relação teoria - prática, o professor da área de química, em sua disciplina, envolve bem a parte experimental, por isso é muito importante para o aluno a vivência em laboratório.

Outro procedimento encontrado pela maioria dos professores é o feedback. Este retorno do professor sobre o rendimento do aluno é muito importante, pois permite a este redirecionar seus estudos em função da orientação do professor.

As práticas avaliativas que são comuns em todos os níveis de ensino são: o feedback, a prova escrita com ou sem consulta e os seminários. Além de utilizar essas estratégias, os professores acreditam que a qualidade da instrução aumenta quando a avaliação é vista como um instrumento de ensino, sendo feita na forma de observações contínuas. Dentre as práticas avaliativas analisadas, as mais típicas do ensino superior são: a cobrança de artigos a serem publicados em revista científica, a participação em congressos e eventos da área durante o curso, o trabalho de campo, os seminários com intervenções e a participação em projetos.

\section{Hipóteses de Solução}

Esta etapa tem como finalidade apontar alternativas de solução para o problema levantado, como uma preparação para a intervenção da realidade estudada. Considerando que buscamos responder: $\mathrm{O}$ que há de específico no ensino superior? Apontamos aqui algumas das possíveis soluções para esse problema: 
A realização, pela UEL, de um curso de formação continuada para seus professores, independentemente dos seus cursos de formação. A avaliação é um componente pedagógico que nem todos possuem em sua formação inicial.

O conhecimento deste relatório de pesquisa pelos docentes dos cursos de ensino superior, para que possam melhor adequar sua prática avaliativa.

Um maior comprometimento por parte dos docentes em apoiar e incentivar seus alunos para participação em congressos e publicação de artigos, já que esta é uma das formas próprias de se trabalhar a avaliação no Ensino Superior.

A promoção de encontros com debates e palestras pelos Departamentos dos cursos de graduação, para que os docentes possam discutir suas práticas avaliativas.

O contato com este estudo pelos professores, para que possam conscientizar-se de seu papel avaliador, de modo que eles se tornem mais críticos quanto a isto e valorizem assim o processo pedagógico.

A realização de outras pesquisas a respeito do tema pelos docentes da área de Educação, a fim de levar mais conhecimento para os profissionais da área e do ensino superior como um todo.

A assunção do caráter de relevância da avaliação da aprendizagem no Ensino Superior pelos docentes, de forma correspondente à proposta de ensinoaprendizagem que cada curso tem, na maioria das vezes voltada para a aprendizagem e o desenvolvimento do profissional e do cidadão.

Tais hipóteses foram pensadas como possíveis contribuições para a construção de práticas avaliativas específicas ou mais apropriadas para o Ensino Superior.

\section{Aplicação à Realidade}

Esta etapa da Metodologia da Problematização contempla o comprometimento do pesquisador com a sua atuação na realidade, selecionando, entre as possíveis soluções encontradas, uma ou mais para serem executadas, a fim de transformar a parcela da realidade estudada, em algum grau. A fim de contribuir para a formação do professor universitário, no que diz respeito às suas práticas avaliativas no Ensino Superior, afirmamos o compromisso de efetuar as seguintes ações:

Encaminhar uma cópia do relatório de pesquisa aos colegiados dos cursos de Licenciatura.

Disponibilizá-la no Acervo da Biblioteca Central da UEL, para que discentes e docentes de outros cursos possam ter acesso à esta pesquisa, e divulgála também.

Como profissionais, esperamos poder extrair das práticas avaliativas positivas aqui descritas, lições / ensinamentos para conduzir nossa prática educacional.

\section{Conclusão}

A avaliação no Ensino Superior sofre a influência de toda uma produção acadêmica que permeia o trabalho docente. Com efeito, o que se publica a respeito do assunto tem sempre o objetivo de melhorar a qualidade de ensino/avaliação. Diante disso, o educador de licenciatura deve preocupar-se em formar o cidadão para que este se volte para as questões mais amplas desta sociedade, sobretudo para os princípios de desenvolvimento autônomo do ser humano, como sujeito social.

Concluímos, por meio das análises, que há uma constante preocupação por parte de alguns docentes em fazer com que os alunos não trabalhem apenas em função da nota e dos certificados. Seguindo esta postura, a vida profissional dos alunos passa a ser influenciada em parte pelo seu histórico, e a vida profissional dos professores de pós-graduação passa a ser influenciada pelo resultado da avaliação dos cursos nos quais trabalham.

Focalizando o grupo de educadores universitários, dentre os diversos grupos que se constituíram nessa pesquisa, pode-se concluir que a avaliação na Educação Superior deve ser entendida como um processo mais amplo, que tem finalidade específica de estimular o desenvolvimento do espírito cientifico e do pensamento reflexivo, bem como promover o 
desejo pelo aperfeiçoamento, com os quais os conhecimentos adquiridos vão se completando. Concluiu-se que as práticas avaliativas mais específicas são: publicação de artigos, participação em projetos, seminários com intervenções e trabalhos de campo.

Integrando a teoria com a prática, o professor de Ensino Superior deve avaliar os alunos em um contexto que valorize a autonomia, a criatividade, a criticidade e a dúvida epistemológica, e para que isso ocorra, ele precisa ter domínio do conhecimento pedagógico, que inclui desde a criatividade em aula até o domínio do espaço e tempo. Com isso, pode-se trabalhar com variadas estratégias de comunicação e tratamento dos conteúdos.

Dessa forma, estar-se-iam produzindo condições para fazer avançar as práticas do ensinar/aprender/ avaliar, no Ensino Superior, no sentido colocado pelos docentes. Isso foi explicitado no Plano Nacional de Educação, que aponta para a solidariedade, o conhecimento, a autonomia, a criticidade e a ampliação da cidadania, pois não se pode perder o foco de que esses profissionais estão formando professores, que, por sua vez, também atuarão na educação e na sociedade.

\section{Referências}

ALMEIDA, A. M. F. P. A avaliação da aprendizagem e seus desdobramentos. Revista de Avaliação Institucional da Educação Superior, Campinas, v.2, n.2, 1997.

BELONI, I. Avaliação do ensino de graduação. Brasília: UNB, 1980.

BERBEL, N. A. N. Metodologia da Problematização: uma alternativa metodológica apropriada para o Ensino Superior. Semina: Ciências Sociais/Humanas, Londrina, v.16, n.2., ed. esp., p.9-19, out. 1995.

(Org.). Metodologia da problematização: fundamentos e aplicações. Londrina: UEL, 1999.

(Org.). Avaliação da aprendizagem no ensino superior: um retrato em cinco dimensões. Londrina: UEL, 2001.
BLOOM, B. S., HASTINGS, J. T.; MADAUS, G. F. Manual de avaliação formativa e somativa do aprendizado escolar. São Paulo: Pioneira, 1983.

BONNIOL, J. J. Modelos de avaliação: textos fundamentais. Porto Alegre: Artmed, 2001.

BRASIL. Regimento Geral da Universidade Estadual de Londrina. Londrina: Eduel, 2005.

BRITO, M. R. F. de. Uma análise fenomenológica da avaliação. São Paulo, 1984. Tese (Doutorado) - Pontifícia Universidade Católica de São Paulo, São Paulo.

COÊLHO, I. M. Avaliação institucional na universidade Pública. Revista da Rede de Avaliação Institucional da Educação Superior, Campinas, v.2, n.3, p.43-51, set. 1997.

CRUZ, D. M. Aprender e ensinar através de videoconferência: percepções e estratégias de alunos e professores num ambiente tecnológico interativo. Tecnologia Educacional, Rio de Janeiro, v.29, n.145, p.4$10,1999$.

CUNHA, M. I. da. Avaliação da educação superior Contribuição aos estudos da Comissão especial de Avaliação. Brasília: SESu, 2003.

DIAS SOBRINHO, J. Avaliação da educação superior. Petrópolis: Vozes, 2000.

FREIRE, P. Pedagogia da autonomia: saberes necessários à prática educativa. São Paulo: Paz e Terra, 1996. (Coleção Leitura).

GANDIN, D. Planejamento como prática educativa. São Paulo: Loyola, 1995.

GODOY, A. S. Avaliação da aprendizagem no ensino superior: estado da arte. Didática, Marília, v.30, p.9-25, 1995.

HAYDT, R. C. Avaliação do processo ensinoaprendizagem. São Paulo: Ática, 1995.

HOFMANN, J. M. L. Avaliar para promover: as setas do caminho. 2.ed. Porto Alegre: Mediação, 2002.

HOOFMANN, J. Avaliação: um olhar construtivo sobre a educação. In.: ENCONTRO NACIONAL DE DIDÁTICA E PRÁTICA DE ENSINO, 8., 1996. Florianópolis. Anais. Florianópolis, 1996.

LUCKESI, C. C. Avaliação da aprendizagem escolar: estudos e proposições. 10.ed. São Paulo: Cortez, 2000.

MINISTÉRIO DA EDUCAÇÃO.- Sistema Nacional de Avaliação da Educação Superior. Brasília: Ministério da Educação, 2004. 
MINISTÉRIODAEDUCAÇÃO. INSTITUTO NACIONAL DEESTUDOS E PESQUISAS EDUCACIONAIS ANÍSIO TEIXEIRA (INEP). $L E I N^{\circ} 10.861, D E 14$ DE ABRIL DE 2004. Disponível em: <www.inep.gov.br/superior/enade/ >. Acesso em: 20 abr. 2004.

MIRAS, M.; SOLÉ, I. A evolução da aprendizagem e a evolução do processo ensino aprendizagem In: COLL, C.; PALACIOS, J.; MARCHESI, A. Desenvolvimento psicológico e educação: psicologia da educação. Porto Alegre: Artes Médicas, 1996. p.9-23

OLIVEIRA, A. A. B.; PALMA, A. P. T. V.; PALMA, J. A. V. Avaliação em educação física: Verificando Possibilidades. Revista Teoria e Prática da Educação, Maringá, v.5, n.11, p.45-54, set/2002.

OLIVEIRA, C. C. Dimensão Instrumental. In: BERBEL, N. A. N.; VASCONCELLOS, M. M. M.; OLIVEIRA, C. C.; COSTA, W.; GOMES, I. R. L .E. Avaliação da aprendizagem no ensino superior: um retrato em cinco dimensões. Londrina: Eduel, 2001, 268p.

PERRENOUD, P. Pedagogia diferenciada: das intenções à ação. Porto alegre: Artes Médicas Sul, 2000.
SAUL, A. M. Avaliação emancipatória: desafios à teoria e prática de avaliação e reformulação política. 33 ed. Campinas: Autores Associados, 2000. (Coleção Polêmicas do Nosso Tempo).

SORDI, M. R.. A prática de avaliação do ensino superior: uma experiência na enfermagem. São Paulo: Cortez/ PUCCAMP, 1995.

VASCONCELLOS, C. S. Avaliação: concepção dialética libertadora do processo de avaliação escolar. 3. ed. São Paulo: Libertad, 1998.

VASCONCELLOS, M. M. M. Dimensão ética. In: BERBEL, N. A. N.; VASCONCELLOS, M. M. M.; OLIVEIRA, C.C.; COSTA, W.; GOMES, I. R. L .E.. Avaliação da aprendizagem no ensino superior. Londrina: Eduel, 2001, 272p.

VIANNA, H. M. Avaliação educacional: uma perspectiva histórica. Estudos em Avaliação Educacional, São Paulo, v.12, p.7-24, 1995.

WEBER, S. Avaliação da educação superior: contribuição aos estudos da Comissão Especial de Avaliação. Brasília: SESu, 2003. 